\title{
Introduction to the Special Thematic Section on "Dynamic Assessment of Men Facing Indeterminate Detention"
}

\author{
Andrew J. R. Harris ${ }^{1}$, Mark E. Olver ${ }^{2}$
}

[1] Private practice, Kawartha Lakes, Ontario, Canada. [2] Psychology, University of Saskatchewan, Saskatoon, Canada.

Sexual Offending: Theory, Research, and Prevention, 2021, Vol. 16, Article e4589, https://doi.org/10.5964/sotrap.4589

Published (VoR): 2021-12-23

Corresponding Author: Andrew J. R. Harris, 74 Butternut Drive, Kawartha Lakes, Ontario, Canada, K9V-4R1. Email: Andrew@offenderrisk.com

Related: This article is part of the SOTRAP Special Thematic Section "Dynamic Assessment of Men Facing Indeterminate Detention", Guest Editors: Andrew J. R. Harris \& Mark E. Olver, Sexual Offending: Theory, Research, and Prevention, 16, https://doi.org/10.5964/sotrap.v16

On behalf of all authors, welcome to this Special Thematic Section of Sexual Offending: Theory, Research, and Prevention (SOTRAP) on use of dynamic assessment with men facing sanctions of indeterminate detention. There are opposing views on the utility of dynamic assessment with men adjudicated for sexual offences generally, but its use with those facing or emerging from Indeterminate Detention (ID) is particularly contentious.

This Special Thematic Section expands an afternoon-long symposium held at the 2018 Association for the Treatment of Sexual Abusers (ATSA) conference in Vancouver, Canada. This symposium was spurred by extensive debate at the 2017 ATSA conference in Kansas City and at the Canadian Psychological Association conference in May 2018, in Halifax, about whether the dynamic assessment of recidivism risk should be used with men designated Sexually Violent Predators/Persons (SVPs; USA), Civil Commitment cases, Dangerous Offenders (Canada), and other forms of indeterminate detention.

The value of dynamic assessment has not been unquestionably established in ID populations. Some argue that the presence of any dynamic risk factors evident in the man indicate his risk is greater than that estimated by static assessment and hence, items on dynamic assessment instruments are represented as risk aggravating factors. Some feel confident in picking individual dynamic factors they feel are applicable to the individual case before them, but do not use the same predictors with all men. Critics claim that dynamic assessment tools do not contain or attempt to assess all possible dynamic risk factors and argue that an incomplete attempt is worse than no attempt at all. 
Still others assert that looking at any criminogenic needs devalues the effectiveness of legally adjudicated punishment. All of the above eschew the use of published actuarially adjusted recidivism estimates.

Reasonable concerns remain whether dynamic assessments should be used to guide treatment and release decisions where there are no longitudinal, long-term follow-up studies with large sample sizes compiled into a comprehensive meta-analysis; believing until these conditions arrive, any use of these measures with indeterminately sentenced men is unethical. Others question whether treatment gains shown in custody are reliable given the constraints of the correctional environment and whether it is possible that this learning could generalize to the community should release ever be granted. Instructing dynamic assessment internationally, I have had national managers for sexual recidivism assessment tell me that they dare not tie their assessments to actuarial or structured professional judgement tools as that would leave them no room to adjust assessments in high visibility/notoriety cases where judicial or political pressure was likely to be applied. Both officials feared for their livelihoods should they advocate for actuarial methodologies. Obviously, we all work in complex circumstances. I believe this Special Thematic Section will present information allowing you to decide for yourself what part dynamic assessment should play in your ID assessments.

\section{The Symposium}

This symposium had a short introduction and then five data-based presentations resulting in the papers in this issue and an extended period of questions and discussion from those in the audience. The first symposium presentation was given by Yolanda Fernandez reviewing how to assess dynamic risk within a maximum secure environment. Dr. Fernandez concedes that assessing dynamic change in risk factors within a secure environment is a challenge as there are fewer opportunities for detainees to demonstrate positive or negative behaviours or learned skills. Dr. Fernandez discusses the types of information available within a maximum secure environment and how to use this information effectively and her data demonstrates good to excellent inter-rater reliability is achievable in 'real world' institutional conditions. Dr. Fernandez presents an intellectually intriguing proposition of viewing institutional sources of information "through a lens focused on identifying proxies or 'functionally equivalent' behaviours" to the identified dynamic risk factors and invites the reader to consider Offence Paralleling Behaviours, Offence Analogue Behaviours, and Offence Replacement Behaviours. In conclusion Dr. Fernandez provides seven keys to the successful implementation of dynamic assessment within the institution.

Jan Looman presents the predictive validity of STABLE-2007 in an incarcerated sample within a maximum-secure environment, a Correctional Service of Canada (CSC) regional treatment centre. The CSC defines a regional treatment centre as a recognized 
hospital and/or psychiatric hospital mandated to accommodate men unable to function in parent institutions due to a mental disorder, cognitive impairment, and/or physical disability typically associated with aging, or who require specialized assessments and as such operates in a manner not unlike specialized hospitals in other jurisdictions. Dr. Looman's paper presents data from two distinct samples, one average risk general sample of men adjudicated for sexual offences and another high-risk/high-needs sample of men who would have similar risk profiles to those found in samples of Dangerous Offenders or SVP's. STABLE-2007 predicted recidivism in both samples, even after taking Static-99R into consideration, but even more interesting is that STABLE-2007 was not a significant predictor when a compound outcome variable (sexual + violent recidivism) was the target. This suggests that STABLE-2007 items target sex recidivism specific constructs and not general violence or antisocial traits.

Mark Olver presents the Violence Risk Scale - Sexual Offense Version (VRS-SO), a dynamic sexual violence risk assessment and treatment planning tool. The VRS-SO tracks personal change across time with reference to the Stages of Change Model (Prochaska et al., 1992, https://doi.org/10.1037/0003-066X.47.9.1102). Dr. Olver uses three High-Risk/High-Needs data sets and a comparison sample of Dangerous Offenders. VRS-SO data suggest that men held under orders of indeterminate detention are not meaningfully of greater risk or need than men of the same risk level who did not receive an indeterminate sentence. Dr. Olver puts forth five propositions for discussion: treating, reintegrating, and releasing High-Risk/High Needs men is "Business as Usual”, Dangerous Offenders have similar risk-needs profiles as other High-Risk/High-Needs cases, Dangerous Offenders can make risk relevant changes and benefit from risk management interventions, Dangerous Offender recidivism rates are not necessarily higher than those of other High-Risk/High-Needs men, and dynamic sexual recidivism risk assessment tools have utility in the management of Dangerous Offenders.

Next Sharon Kelley writes on the most promising new wave in dynamic assessment - the assessment of protective factors - reflecting a strengths-based approach. Protective factors reduce risk, representing skills or abilities the man now displays or factors that counteract known risk factors. Dr. Kelley answers three direct questions: first, how evaluators assess treatment gains should they elect not to use a standard dynamic assessment, including the consequences of using a Bayesian approach; second, is there sufficient empirical support for the use of dynamic assessment measures; and third, can these tools be used to advantage in SVP populations? Dr. Kelley presents data showing these assessments are helpful in preparing and planning for conditional release, and going further, showing that SVP evaluations tend to demonstrate more risk factors than non-SVP evaluations. Dr. Kelley also presents data on SVP treatment gains as assessed using the VRS-SO. The assessment of protective factors increases the likelihood of a balanced and transparent evaluation where standards are set and can be used to report to the court factors that mitigate or increase risk. 
To round out the Special Thematic Section Brian Abbot tackled the question of whether dynamic assessment is a sufficiently mature methodology to be used with this population. In his paper Dr. Abbott reviews the SVP commitment criteria and discusses whether dynamic assessment provides probative information to release decision makers. Dr. Abbott includes information on operational differences between those assessors who use a standardized assessment of dynamic factors in contrast to those assessors who select dynamic constructs they believe apply individually to individual men. Dr. Abbott reveals that some constructs in common use or recommended in the literature may not have sufficient science behind them and comprehensively reviews concerns about the use of STABLE-2007, including concerns anchored in proper administration, predictive validity, and questioning the combination of Static-99R and STABLE-2007 scores for a cumulative measure. Citing the VRS-SO, Dr. Abbott discusses the validity of comparing study results of men who have engaged in treatment to men of SVP status who often have not engaged in treatment, providing several enlightening conclusions.

The impetus for the symposium and this Special Thematic Section was to give an opportunity for informed debate and a platform for information sharing on the current state of dynamic assessment for those men involved in or facing an indeterminate sentence. All contributors hope that the elucidation and debates you will find herein will stir further research in this important area and that this Special Thematic Section will provide a waypoint in efforts to improve the management of risk in men who have committed serious sexual offences.

Andrew 7. R. Harris, Symposium Chair

Mark E. Olver, Managing editor for this issue

Funding: The authors have no funding to report.

Acknowledgments: The authors have no additional (i.e., non-financial) support to report.

Competing Interests: The authors have declared that no competing interests exist.

\section{IATSO}

Internationol Assocition for the
Ireatmen of Sexvul Offenders

Sexual Offending: Theory, Research, and Prevention (SOTRAP) is the official journal of the International Association for the Treatment of Sexual Offenders (IATSO).
(P) leibniz-psychology.org

PsychOpen GOLD is a publishing service by Leibniz Institute for Psychology (ZPID), Germany. 